\title{
EFEKTIVITAS KONSENTRASI EKSTRAK BIJI SIRSAK GUNUNG (Annona montana Macf.) TERHADAP MORTALITAS RAYAP TANAH (Coptotermes curvignathus Holmgren, Rhinotermitidae)
}

\author{
Agus Ismanto $\left.{ }^{1 *}\right)^{*}$, Moerfiah $^{2)}$, Achmad Supriadi $^{1)}$, Muhamad Nizar Zulfikar ${ }^{2)}$ \\ ${ }^{1)}$ Pusat Penelitian dan Pengembangan Hasil Hutan \\ Jalan Gunung Batu No. 5, Bogor 16610 \\ ${ }^{2)}$ Program Studi Biologi - FMIPA, Universitas Pakuan \\ Jalan Pakuan PO Box 452, Bogor 16143 \\ *e-mail: ismanto_agus@yahoo.com
}

\section{ABSTRACT \\ The Effectiveness of The Concentration of Mountain Soursop Extract (Annona montana macf.) on The Mortality of Subterranean Termite (Coptotermes curvignathus Holmgren, Rhinotermitidae)}

\begin{abstract}
Termites cause a lot of harm. Termites can damage the building components and the contents of the building in the form of furniture, books, cloth, and even securities. One example of a termite species that is dangerous as a pest is Coptotermes curvignathus. Mountain soursop seeds have bioactive compounds that are very cytotoxic, so they have potential as insecticides. This research Used a Completely Randomized Design (CRD) consisting of controls and 5 treatments (P1) 20\%, (P2) 40\%, (P3) 60\%, (P4) 80\% (P5) 100\% mountain soursop seed extract. The parameters observed were retention, termite mortality, and weight reduction in the test sample. Mountain soursop seed extract is effective as an insecticide against subterranean termites. The concentration of mountain soursop seed extract $40 \%(P 2)$ causes termite mortality of $100 \%$ and a decrease in sample weight by $0.43 \%$. Mountain soursop seed extract has the potential to be developed as an anti-termite species $C$. curvignathus Holmgren. The retention value shows that the mountain soursop seed extract with a concentration of $20 \%(P 1)$ meets the standard retention of interior wood use, while extracts with a concentration of $40 \%(P 2)$ meet the standard of retention of exterior wood use.
\end{abstract}

Keywords: Mountain soursop seeds, Retention, mortality, weight decrease, Subterranean Termite

\begin{abstract}
ABSTRAK
Rayap banyak menimbulkan kerugian. Rayap dapat merusak komponen bangunan beserta isi bangunannya seperti furnitur, kertas, bahan kain dan lain-lain. Salah satu contoh spesies rayap yang berbahaya sebagai hama adalah Coptotermes curvignathus. Biji sirsak gunung memiliki senyawa bioaktif bersifat sitotoksik yang sangat kuat, sehingga memiliki potensi sebagai insektisida. Rancangan penelitian menggunakan Rancangan Acak Lengkap (RAL), terdiri dari 6 perlakuan yaitu (P1) 20\%, (P2) 40\%, (P3) 60\%, (P4) 80\% (P5) 100\% dan kontrol. Parameter yang diamati meliputi retensi, mortalitas rayap, dan penurunan berat sampel. Ekstrak biji sirsak gunung efektif sebagai insektisida terhadap rayap tanah. Konsentrasi ekstrak biji sirsak gunung 40\% (P2) menyebabkan mortalitas rayap sebesar $100 \%$ dan penurunan berat contoh uji sebesar 0,43\%. Ekstrak biji sirsak gunung berpotensi dikembangkan sebagai anti rayap tanah jenis $C$. curvignathus Holmgren. Nilai retensi menunjukkan bahwa ekstrak biji sirsak gunung dengan konsentrasi 20\% (P1) memenuhi standar retensi penggunaan kayu interior, sementara ekstrak dengan konsentrasi 40\% (P2) memenuhi standar retensi penggunaan kayu eksterior.
\end{abstract}

Kata kunci: Biji sirsak gunung, retensi, mortalitas, penurunan berat, rayap tanah

\section{PENDAHULUAN}

Intensitas serangan rayap pada bangunan semakin tinggi dan meluas sehingga menimbulkan peingkatan kerugian tiap tahun (Savitri et al., 2016). Kerugian ekonomis yang diakibatkan oleh serangan rayap pada tahun 1995 mencapai Rp. 1,67 trilyun, tahun 2000 mencapai Rp. 2,79 trilyun, tahun 2010 mencapai Rp. 5,17 trilyun, dan tahun 2015 Rp. 8,68 trilyun (Nandika et al., 2015). Salah satu contoh spesies rayap yang berbahaya sebagai hama adalah Coptotermes curvignathus (Nandika et al., 2015). Rayap banyak menimbulkan kerugian bagi manusia seperti rusaknya komponen. Komponen bangunan yang harus diganti akibat kerusakan kayu oleh 
organisme perusak menimbulkan pemborosan sumber daya hutan (Barly \& Ismanto, 2008). Untuk mengatasi hal tersebut kayu diawetkan sehingga pemakaiannya lebih tahan lama (Toleng et al., 2014).

Sampai saat ini, hampir semua pengawet kayu merupakan bahan sintetis yang dapat berdampak negatif terhadap lingkungan. Untuk menekan dampak negatif ini, diperlukan cara pengendalian yang lebih ekonomis dan tidak mencemari lingkungan. Oleh sebab itu, dibutuhkan cara pengawetan yang ramah lingkungan, seperti penggunaan pestisida nabati (Ismanto et al., 2009). Gerakan penggunaan pestisida alami yang ramah lingkungan mendorong masyarakat kembali melirik produk-produk alami (Rizal et al., 2005). Beberapa jenis tumbuhan telah banyak digunakan sebagai pestisida nabati karena bahan aktifnya.

Saat ini banyak dikaji penggunaan bahan pengawet alami ekstrak berbagai tanaman untuk pengawet kayu (Toleng et al., 2014). Pemanfaatan senyawa alami tumbuhan yang memiliki sifat racun serangga, khususnya untuk rayap, dapat diperoleh salah satunya dari famili Annonaceae. Famili Annonaceae memiliki produk metabolit sekunder dengan aktivitas insektisida tinggi (Ribeiro et al., 2016). Biji sirsak gunung memiliki produk metabolit sekunder alkaloid dan asetogenin. Asetogenin adalah senyawa bioaktif bersifat sitotoksik yang sangat kuat, sehingga memiliki potensi sebagai insektisida (Blessing et al., 2010). Bandeira et al., (2017) menyatakan bahwa ekstrak biji sirsak gunung (Annona montana Macf.) dapat menyebabkan mortalitas pada hama kutu daun (Aphis craccivora Koch.) 96,64\%. Oleh karena itu dalam penelitian ini ekstrak biji sirsak gunung akan diuji sebagai pestisida nabati rayap tanah (Coptotermes curvignathus Holmgren)

\section{BAHAN DAN METODE}

\section{Bahan dan Alat}

Bahan yang digunakan adalah contoh uji kayu pinus (Pinus merkusii), pasir, ekstrak biji sirsak gunung (A. montana), aquades, tween 80 , dan serangga uji rayap tanah (C. curvignathus) jenis pekerja dan prajurit.

Alat-alat yang digunakan yaitu alat tulis, alat dokumentasi, gelas piala, gelas ukur, pipet, jangka sorong, bulu ayam, timbangan, dan jampot/botol kaca.

\section{Metode}

\section{Persiapan Contoh Uji Kayu}

Contoh uji kayu pinus dipotong dengan ukuran panjang $2,5 \mathrm{~cm} \times$ lebar 2,5 $\mathrm{cm} \times$ tebal $0,5 \mathrm{~cm}$, berdasarkan acuan pada SNI 01.7207-2006. Jumlah contoh uji yang dibuat sebanyak 30 buah, terdiri dari 5 buah contoh uji sebagai kontrol dan masingmasing 5 buah contoh uji untuk setiap perlakuan dengan lima kali ulangan (25 contoh uji).

\section{Pembuatan Larutan}

Larutan ekstrak diencerkan dengan menggunakan aquades dan ditambahkan 1 $\mathrm{mL}$ tween 80 sebagai emulsifier untuk dibuat konsentrasi tertentu $(0,20,40,60,80$, 100\%) (Oktapiani, 2018).

\section{Proses Pengawetan Rendaman Dingin dan Retensi}

Cara pengawetan rendaman dingin dan pengujian retensi mengacu pada SNI 033233-1992 (BSN, 1992). Contoh uji kayu pinus (Pinus merkusii) dikering udarakan hingga mencapai $<14 \% \quad\left(\mathrm{~B}_{0}\right)$, kemudian contoh uji dikeringkan dalam oven, selanjutnya contoh uji direndam dengan larutan ekstrak biji sirsak gunung selama 48 jam. Setelah direndam selama 48 jam, contoh uji diangkat dan ditiriskan dan kemudian ditimbang $\left(\mathrm{B}_{1}\right)$. Retensi dihitung berdasarkan perbandingan selisih berat kayu berat kayu dengan volume kayu dalam satuan $\left(\mathrm{kg} / \mathrm{m}^{3}\right)$ (Karlinasari et al., 2010). Retensi larutan ekstrak menggunakan rumus berikut:

Keterangan

$$
\mathrm{R}=\frac{\mathrm{B}_{1}-\mathrm{B}_{0}}{\mathrm{~V}} \mathrm{x} \mathrm{K}
$$

$\mathrm{R}=$ Retensi bahan pengawet $\left(\mathrm{kg} / \mathrm{m}^{3}\right)$

$\mathrm{B}_{0}=$ Berat contoh uji sebelum diawetkan $(\mathrm{kg})$

$\mathrm{B}_{1}=$ Berat contoh uji setelah diawetkan $(\mathrm{kg})$

$\mathrm{V}=$ Volume contoh uji $\left(\mathrm{m}^{3}\right)$

$\mathrm{K}=$ Konsentrasi bahan pengawet (\%) 


\section{Uji Ketahanan Kayu Terhadap Rayap Tanah}

Tata cara pengujian ketahan kayu terhadap rayap tanah berdasarkan pada SNI 01.7207-2006. Nilai mortalitas rayap setelah pengumpanan rayap tanah (C. curvignathus) dihitung menggunakan rumus berikut:

Keterangan:

$$
\mathrm{MR}=\frac{\mathrm{N}_{2}}{\mathrm{~N}_{1}} \times 100 \%
$$

MR = mortalitas rayap (\%)

$\mathrm{N}_{1} \quad$ = jumlah rayap sebelum pengumpanan (ekor)

$\mathrm{N}_{2} \quad$ = jumlah rayap mati setelah pengumpanan (ekor)

Nilai penurunan berat contoh uji kayu dihitung menggunakan persamaan berikut:

Keterangan:

$$
\mathrm{P}=\frac{\mathrm{W}_{1}-\mathrm{W}_{2}}{\mathrm{~W}_{1}} \times 100 \%
$$

$\mathrm{P} \quad=$ penurunan berat $(\%)$;

$\mathrm{W}_{1}$ = berat kering kayu sebelum diumpankan $(\mathrm{kg})$

$\mathrm{W}_{2}$ = berat kering kayu setelah diumpankan $(\mathrm{kg})$

Penentuan ketahanan kayu berdasarkan penurunan berat terhadap rayap tanah, sesuai dengan SNI 01.7207-2006 (BSN, 2006).

\section{HASIL DAN PEMBAHASAN}

\section{Retensi}

Bahan pengawet yang masuk ke dalam kayu ditentukan dengan pengukuran retensi (Tabel 1).

Tabel 1. Rata-rata Retensi

\begin{tabular}{cc}
\hline Perlakuan & Retensi $\left(\mathrm{kg} / \mathrm{m}^{3}\right)$ \\
\hline P1 $(20 \%)$ & $10,36 \pm 1,88^{\mathrm{a}}$ \\
P2 $(40 \%)$ & $49,69 \pm 7,87^{\mathrm{b}}$ \\
P3 $(60 \%)$ & $194,74 \pm 11,14^{\mathrm{c}}$ \\
P4 $(80 \%)$ & $284,07 \pm 21,59^{\mathrm{d}}$ \\
P5 (100\%) & $386,49 \pm 19,90^{\mathrm{e}}$ \\
\hline Keterangan: Angka rata-rata yang diikuti huruf \\
superskrip berbeda pada kolom/baris \\
yang sama menunjukkan pengaruh yang \\
berbeda nyata $(\mathrm{p}<0,05)$
\end{tabular}

Pengamatan untuk mengetahui nilai retensi ekstrak biji sirsak gunung pada contoh uji kayu dapat diketahui setelah 2 hari masa perendaman. Nilai rata-rata retensi bahan pengawet pada berbagai tingkat konsentrasi menunjukkan semakin meningkat, seiring dengan meningkatnya konsentrasi bahan pengawet. Nilai rata-rata terendah ditunjukkan pada konsentrasi $20 \%$ (P1) sebesar $10,36 \mathrm{~kg} / \mathrm{m}^{3}$ dan nilai retensi tertinggi pada konsentrasi $100 \%$ (P5) sebesar 386,49 kg/m ${ }^{3}$. Menurut (Prawira et al., 2013) hal ini dikarenakan resapan bahan pengawet terhadap kayu lebih banyak daripada konsentrasi rendah. Hasil penelitian menujukkan bahwa nilai retensi ekstrak biji sirsak gunung berdasarkan perbedaan konsentrasi mempunyai nilai retensi yang berbeda. Sejalan dengan penelitian Mariana et al. (2013), pada pengawetan kayu durian (Durio zibethinus) dengan menggunakan ekstrak daun kumis kucing (Orthosiphon aristatus) pada tingkat konsentrasi 0,09\%, dapat menghasilkan nilai retensi terendah sebesar $0,926 \mathrm{~g} / \mathrm{cm}^{3}$ dan konsentrasi $23,07 \%$ dapat menghasilkan nilai retensi tertinggi sebesar 2,408 g/ $\mathrm{cm}^{3}$. Menurut (Mariana et al., 2013), besarnya konsentrasi bahan pengawet sebanding dengan nilai retensi yang akan dicapai. Meskipun demikian, retensi dapat dihasilkan berbeda pada konsentrasi yang sama karena factor ukuran dan volume kayu (Barly et al., 2010). Konsentrasi tinggi mengandung zat ekstrak lebih banyak kemudian mengendap di dalam sel-sel kayu (Sukarya, 2015).

Nilai Retensi minimum yang disyaratkan pada SNI 01-5010.1-1999 untuk pemakaian di dalam bangunan (interior) dan di luar bangunan (eksterior) adalah 8,2 dan $11,3 \mathrm{~kg} / \mathrm{m}^{3}$. Contoh uji P1 sudah memenuhi standar SNI untuk pemakaian kayu pada gedung/bangunan dibawah atap, tetapi belum memenuhi nilai retensi yang dipersyaratkan untuk digunakan di luar atap. Contoh uji P2 sudah memenuhi standar SNI untuk pemakaian dalam maupun luar gedung/bangunan yaitu $>8,2 \mathrm{~kg} / \mathrm{m}^{3}$ untuk interior dan $11,3 \mathrm{~kg} / \mathrm{m}^{3}$ untuk eksterior

\section{Mortalitas Rayap}

Mortalitas rayap merupakan tingkat kematian rayap yang terjadi selama 4 minggu pegujian. Mortalitas rayap ini memberikan gambaran seberapa besar tingkat toksisitas zat ekstrak terhadap kematian rayap tanah. Nilai mortalitas rayap dapat dilihat pada Tabel 2. 
Tabel 2. Rata-rata Mortalitas Rayap

\begin{tabular}{cc}
\hline Perlakuan & $\begin{array}{c}\text { Mortalitas Rayap } \\
(\%)\end{array}$ \\
\hline Kontrol & $21 \pm 4,73^{\mathrm{a}}$ \\
P1 $(20 \%)$ & $94,80 \pm 2,14^{\mathrm{b}}$ \\
P2 $(40 \%)$ & $100 \pm 0^{\mathrm{c}}$ \\
P3 $(60 \%)$ & $100 \pm 0^{\mathrm{c}}$ \\
P4 (80\%) & $100 \pm 0^{\mathrm{c}}$ \\
P5 (100\%) & $100 \pm 0^{\mathrm{c}}$ \\
\hline Keterangan: Angka rata-rata yang dikuti huruf \\
\multicolumn{2}{c}{ superskrip berbeda pada kolom/baris } \\
\multicolumn{2}{c}{ yang sama menunjukkan pengaruh } \\
yang berbeda nyata $(\mathrm{p}<0,05)$
\end{tabular}

Nilai mortalitas rayap semakin meningkat seiring dengan meningkatnya konsentrasi bahan pengawet yang disertai jumlah senyawa toksik yang meningkat (Hidayatullah et al., 2017). Persentase mortalitas rayap terendah $(21 \%)$ terdapat pada kontrol, sedangkan mortalitas tertinggi mencapai $100 \%$ ditunjukkan pada konsentrasi seluruh perlakuan. Konsentrasi pengawet yang tinggi mengakibatkan kelangsungan hidup rayap rendah (Oktapiani, 2018). Bandeira et.al. (2017) melaporkan ekstrak biji A. montana yang semakin tinggi memberikan dampak besarnya nilai mortalitas Aphis craccivora.

Senyawa pada ekstrak biji sirsak gunung tidak secara langsung menyebabkan kematian rayap. Mortalitas rayap tersebut diduga karena bahan aktif yang terkandung dalam ekstrak biji sirsak gunung berfungsi dengan baik sebagai insektisida, repellent, dan anti feedant (Oktapiani, 2018). Bandeira et.al. (2017) melaporkan bahwa senyawa bioaktif yang terkandung pada biji sirsak gunung terdiri dari asetogenin dan alkaloid.

Kematian rayap oleh senyawa bioaktif pada ekstrak biji sirsak dapat melalui beberapa kemungkinan mekanisme. Arif et al. (2007) menyatakan, kemungkinan pertama adalah, terganggunya enzim selulase akibat matinya protozoa yang merupakan simbion di dalam perut rayap. Rusaknya enzim selulase berdampak pada pencernaan makanan oleh rayap sehingga rayap tidak mendapatkan energi dan pada akhirnya mati. Senyawa tersebut kontak atau masuk ke dalam tubuh serangga, asetogenin bereaksi melalui kontak atau konsumsi, menghambat kompleks mitokondria I dan mengganggu saluran natrium yang diatur oleh tegangan, mengubah keseimbangan natrium dan kalium, hal ini mencegah transmisi saraf normal dan menyebabkan kelumpuhan diikuti oleh kematian ("Knockdown") (Colom et al., 2007). Kemungkinan mekanisme kematian lainnya yaitu rusaknya sistem saraf yang disebabkan senyawa bioaktif.

\section{Penurunan Berat Contoh Uji}

Penurunan berat contoh uji merupakan berkurangnya berat kayu yang diakibatkan oleh rayap tanah yang memakan contoh uji. Penurunan berat adalah parameter dalam mentukan ketahanan contoh uji terhadap serangan organisme perusak.

Tabel 3. Rata-rata Penurunan Berat Contoh Uji

\begin{tabular}{cc}
\hline Perlakuan & Penurunan Berat (\%) \\
\hline Kontrol & $10,37 \pm 3,65^{\mathrm{a}}$ \\
P1 $(20 \%)$ & $3,39 \pm 0,65^{\mathrm{b}}$ \\
P2 $(40 \%)$ & $0,43 \pm 0,18^{\mathrm{c}}$ \\
P3 $(60 \%)$ & $0,20 \pm 0,20^{\mathrm{c}}$ \\
P4 $(80 \%)$ & $0,07 \pm 0,04^{\mathrm{c}}$ \\
P5 (100\%) & $0,04 \pm 0,01^{\mathrm{c}}$ \\
\hline Keterangan: Angka rata-rata yang diikuti huruf \\
\multicolumn{2}{c}{ superskrip berbeda pada kolom/baris } \\
\multicolumn{2}{c}{ yang sama menunjukkan pengaruh yang } \\
berbeda nyata $(\mathrm{p}<0,05)$
\end{tabular}

Penurunan berat contoh uji yang mengandung ekstrak biji sirsak gunung lebih kecil dibandingkan dengan bobot contoh uji kayu yang tidak mengandung ekstrak (Tabel 3) rataan penurunan berat yang paling besar yaitu sebesar 10,37\%. Menurut Toleng et al. (2014) hal tersebut karena tidak terdapat bahan beracun pada perlakuan contoh uji kontrol, sehingga rayap pemakan kayu tidak terhalangi. Rayap akan lebih leluasa memakan seluruh bagian kayu tanpa ada bahan pelapis maupun pelindung baik pada permukaan kayu maupun dalam kayunya (Mariana et al., 2013).

Pada contoh uji yang diawetkan mengalami penurunan berat pada contoh uji P1 (20\%), sedangkan pada contoh uji P2 hingga P5 contoh uji tidak mengalami penurunan berat. Arbaiatusholeha et al. (2016) melakukan uji menggunakan ekstrak 
tembakau diperoleh hasil konsentrasi ekstrak berbanding terbalik dengan perubahan bobot kertas umpan. Toleng et al., (2014), menyatakan bahwa kualitas kayu semakin baik dengan konsentrasi pengawet yang lebih tinggi. Serangan rayap tanah lebih efektif dicegah dengan campuran bahan pengawet yang pekat (Futariana \& Darmono, 2014)

Senyawa antifeedant berfungsi menghambat daya makan serangga. Ekstrak dengan toksisitas yang semakin tinggi mengakibatkan konsumsi makanan oleh rayap berkurang dan persentase pengurangan berat contoh uji semakin kecil (Arbaiatusholeha et al., 2016).

Berdasarkan SNI 01.7207-2006 (BSN, 2006) pada contoh uji Kontrol (K) menunjukkan bahwa contoh uji tersebut tergolong kayu kelas III (sedang). Setelah pemberian konsentrasi ekstrak biji sirsak gunung contoh uji P1 menjadi kayu kelas II (tahan), pada contoh uji P2 menjadi kayu kelas I (sangat tahan), dengan kata lain pemberian konsentrasi ekstrak biji sirsak gunung dapat meningkatkan daya tahan contoh uji terhadap serangan rayap tanah. Contoh uji yang awalnya tidak tahan terhadap rayap tanah menjadi sangat tahan.

\section{KESIMPULAN}

Ekstrak biji sirsak gunung efektif sebagai insektisida terhadap rayap tanah. Konsentrasi ekstrak biji sirsak gunung $40 \%$ (P2) menyebabkan mortalitas rayap sebesar $100 \%$ dan penurunan berat contoh uji sebesar $0,43 \%$. Perlu dilakukan pengujian terhadap serangga lainnya yang menyerang kayu seperti rayap kayu kering, kumbang bubuk kering, dan lain-lain

\section{DAFTAR PUSTAKA}

Arbaiatusholeha, R., Yuliawati, S. \& Saraswati, L. D. (2016). Uji Efikasi Ekstrak Batang Tembakau (Nicotiana spp.) untuk Pengendalian Rayap Tanah (Coptotermes spp.). Jurnal Kesehatan Masyarakat, 4(1), 206.
Arif, A., Usman, M.N. \& Samma F. (2007). Sifat Anti Rayap dari Ekstrak Ijuk Aren (arenga pinnata Merr.). Jurnal Perrenial. 3(1), 15-17.

Badan Standarisasi Nasional [BSN]. (1992). SNI 03-3233-1992 Tata Cara Pengawetan Kayu untuk Bangunan Rumah dan Gedung. BSN.

Badan Standarisasi Nasional. (1999). SNI 03-5010.1-1999 Pengawetan Кауи untuk Perumahan dan Gedung. BSN.

Badan Standarisasi Nasional. 2006. SNI 017207-2006 Uji Ketahanan Kayu dan Produk Kayu terhadap Organisme Perusak Kayu. BSN

Bandeira, H.F. da S., Lima, A.C.S., Trassato, L.B., Strucker, A. \& Vieira, A. de J. (2017). Bioactivity of Annona montana Macfad Extracts on the Black Cowpea Aphid (Aphis craccivora Koch). Agrária - Revista Brasileira de Ciências Agrárias, 12(1), 41-46.

Barly \& Ismanto, A. (2008). Keefektifan Seng Khlorida-Dikhromat sebagai Bahan Pengawet Kayu. Jurnal Penelitian Hasil Hutan, 26(4), 332.

Barly, Lelana, N.E. \& Ismanto, A. (2010). Keefektifan Campuran Garam Tembaga-Khromium-Boron Terhadap Rayap dan Jamur Perusak Kayu. Jurnal Penelitian Hasil Hutan, 28(3), 227

Blessing, L.D.T., Colom, O.A., Popich, S., Neske, A., \& Bardon, A,. (2010). Antifeedant and Toxic Effects of Acetogenins from Annona montana on Spodoptera frugiperda. Journal of Pest Science, 83, 307-308.

Colom, O.A., Neske, A., Popich, S. \& Bardon, A. (2007). Toxic effects of annonaceous acetogenins from Annona cherimolia (Magnoliales: Annonaceae) on Spodoptera 
frugiperda (Lepidoptera: Noctuidae). Journal of Pest Science, 80, 63.

Futariana, Y.S. \& Darmono. (2014). Pengaruh Awal Pemanfaatan Oli dan Briket Batubara Sebagai Bahan Pengawet Kayu Terhadap Serangan Rayap. Jurnal Teknik Sipil, Universitas Negeri Yogyakarta, 15.

Hidayatullah, S., Rizaldy, A. A., Gracia, H. \& Syahidah. (2017). Efikasi Ekstrak Daun Tuba sebagai Anti Rayap Alami. Jurnal Ilmu Teknologi Kayu Tropis, 15(2), 172.

Ismanto, A., Yuningsih, S., \& Lelana N.E. (2009). Effect of Soursop Seed Oil Extract (Annona muricata L) on Dry Wood Termite Cryptotermes cynocephalus Light Mortality and Attact Degree. Proceedings of The First International Symposium of Indonesian Wood Research Society, 222.

Karlinasari, L., Rahmawati, M \& Mardikanto, T. R. (2010). Pengaruh Pengawetan Kayu Terhadap Kecepatan Gelombang Ultrasonik dan Sifat Mekanis Lentur serta Tekan Sejajar Serat Kayu Acacia mangium Willd. Jurnal Teknik Sipil, 17(3), 165.

Mariana, E., Ariyanti \& Erniwati. (2013). Uji Retensi dan Efektivitas Tanaman Kumis Kucing (Orthosiphon aristatus) terhadap Serangan Rayap Tanah (Coptotermes Sp.) Pada Kayu Durian (Durio zibethinus). Warta Rimba, 1(1), 5.

Nandika, D., Rismayadi, Y. \& Diba, F. (2015). Rayap, Biologi dan Pengendaliannya. (Edisi ke-2). Surakarta: Muhammadiyah University Press. 12-17, 29, 35-51, 58-59.

Nihayah, E. (2014). Sifat Antirayap Zat Ekstraktif Daun Mindi (Melia azedarach linn.) terhadap Rayap Tanah Coptotermes curvignathus
Holmgren. (Skripsi). Fakultas Kehutanan, Institut Pertanian Bogor.

Oktapiani, C. (2018). Potensi Ekstrak Biji Sirsak Gunung (Annona montana) dalam Menggendalikan Serangan Rayap Tanah. (Skripsi). Fakultas Matematika dan Ilmu Pengetahuan Alam, Institut Pertanian Bogor.

Prawira, H., Orahmahi, H. A., Setyawati, D. \& Diba, F. (2013). Aplikasi Asap Cair Dari Kayu Laban (Vitex Pubescens Vahl) Untuk Pengawetan Kayu Karet. Jurnal Hutan Lestari, l(1), 18

Ribeiro, L. P., Ansante, T. F. \& Vendramin, J. D. 2016. Effect of Ethanolic Extract from Annona mucosa Seeds on Development and Feeding Behavior of Spodoptera frugifera. Bragantia, Campinas, 75(3), 322.

Rizal, M., Balfas, R., Rostiana, O., Rosman, R. \& Dwijanti, S.R. (2005). Status Penelitian Pestisida Nabati di BALITTRO. Prosiding Seminar Nasional Pestisida Nabati III. 2 \& 11.

Savitri, A., Martini \& Yuliawati, S. (2016). Keanekaragaman Jenis Rayap Tanah dan Dampak Serangan Pada Bangunan Rumah di Perumahan Kawasan Mijen Kota Semarang. Jurnal Kesehatan Masyarakat, 4(1), 101.

Sukarya, N.K. (2015). Efikasi Ekstrak Daun Sirsak Gunung (Annona montana Macf.) Terhadap Rayap Kayu Kering (Cryptotermes cynocephalus Light.). (Skripsi). Fakultas Kehutanan, Institut Pertanian Bogor.

Toleng, F.N., Erniwati \& Ariyanti. (2014). Retensi dan Efektivitas Bahan Pengawet Ekstrak Daun Cengkeh (Syzygium Aromaticum) pada Kayu Durian (Durio Zibethinus) Terhadap Serangan Rayap Tanah (Coptotermes sp.). Warta Rimba, 2(2),17-18. 